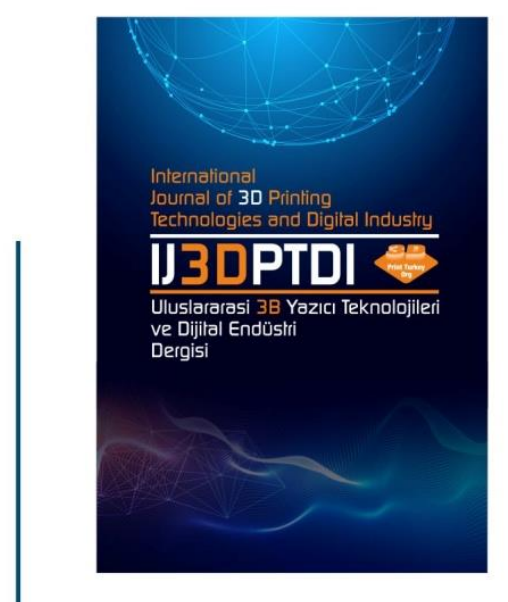

ULUSLARARASI 3B YAZICI TEKNOLOJILERI

VE DIJITAL ENDÜSTRI DERGISI

INTERNATIONAL JOURNAL OF 30 PRINTING TECHNQLOGIES AND DIGITAL INDUSTRY

I55N:2602-3350 [Online]

URL: https://dergipark.org.tr/ij3dptdi

\title{
METHODS AND MEANS OF INCREASING THE ACCURACY OF DETERMINING THE STATE OF THE OBJECT
}

Yazarlar (Authors): Lala Bakirova $\mathbb{D}^{\mathbb{D}}$, Elvira Bunyatova $\mathbb{D}^{\text {* }}$

Bu makaleye şu şekilde atıfta bulunabilirsiniz (To cite to this article): Bakirova L., Bunyatova E., "Methods And Means Of Increasing The Accuracy Of Determining The State Of The Object" Int. J. of 3D Printing Tech. Dig. Ind., 5(3): 469-476, (2021). 


\title{
METHODS AND MEANS OF INCREASING THE ACCURACY OF DETERMINING THE STATE OF THE OBJECT
}

\author{
Lala Bakirova ${ }^{\mathrm{a}}$ iD, Elvira Bunyatova ${ }^{\mathrm{a}}$ iD * \\ ${ }^{a}$ Azerbaijan State Oil and Industry University, Information Technology and Management Faculty, \\ Instrumentation Engineering Department, AZERBAIJAN \\ *Corresponding Author: lala_bekirova@mail.ru
}

(Received: 27.06.2021; Revised: 08.10.2021; Accepted: 22.11.2021)

\begin{abstract}
In this study to determine the state of the object, the distance to it, inclination, density, etc. various types of sensors setting parameters with high accuracy, as well as methods and means to increase the accuracy of setting these parameters are presented in the article. The types of the presented sensors, the principles of operation, areas of application have been comparatively analyzed, their classification has been considered and their pros and cons have been analyzed. Among the considered methods, a complex method with laser sensors, which is an expedient method for determining the distance to the object with high accuracy, has been proposed, the principle-structural model, areas of application, features, advantages, and disadvantages of the functional model have been analyzed. The proposed method with high-temperature stability determines the distance to the object, inclination, density, etc. the possibility of measurement is shown. The optical system, which uses a laser source and sensors being capable of taking measurements in the visible range, is accompanied by perfect control based on sensor circuits and processing microcontrollers to achieve optimal results in the complex measurement and control process that allows determining the characteristic parameters with high accuracy that set the state of a high object.
\end{abstract}

Keywords: Sensor. Laser Sensors. Visible Range. Object. Complex Measurements. Accuracy. Functional Model. Structural Model.

\section{INTRODUCTION}

Measuring the distance between objects or to any object is a topical issue in many industrial and technological applications, geodesy, ecology, robotics, military applications. Laser distance sensors based on the use of finely focused laser beam (visible, red part of the spectrum) for taking accurate measurements have been more widely used recently, and their principle of operation is consistent with the principle of operation of photosensors, being typically equipped with programmable regulators it provides both analog and digital signal output.

As laser distance sensors are contactless optoelectronic devices for measuring the geometric parameters of objects, they are used to measure distance, displacement, length, height, width, diameter, density, roughness, and so on. and their high resolution and ability to measure high-speed vibrations allow the use of laser sensors, and the accuracy obtained at this time can reach onethousandth of the total distance.

As laser sensors are contactless, they can be used to recognize small objects without any contact and to accurately detect their position, and they are able accurately to determine the location and displacement of the object, the distance to the object. Using the visible part of the spectrum, these sensors are dominated by a high detection range, are small in size and consume minimal energy, provide reliable protection against environmental influences as well. When the sensor is contaminated by the impact of the environment, an immediate alarm is sounded, which makes the use of laser sensors even more expedient. The laser sensor uses triangular laser beams to measure the distance to 
the object, and their principle of operation is based on the triangular beam principle, and these laser beams appear as small spots on the object. The visible red part of the light spectrum of laser sensors and laser beam allows the sensor to be easily adjusted to detect very small objects [1]

Laser sensors are widely used not only in industry, mechanical engineering but also in automated security systems, medicine, information sector, communications, defense sector, woodworking and metalworking, construction, and various fields of industry, as well as other areas of life. Considering the influence of external factors, such operating instructions as the effect of ambient temperature, the effect of an alternative magnetic field, acoustic sensitivity, the effect of object deformation, side sensitivity, the influence of cable effect, the effect of surface contours, power supply requirements of vibrating transmitters with built-in electronics should be followed to obtain the correct operation of the sensor and more accurate measurement results [2].

The technical characteristics of laser distance sensors, which show that the sensor models produced by the most famous manufacturers in the world can accurately determine the distance from $100 \mathrm{~m}$ to 3 $\mathrm{km}$, are given in Table 1. [3].

Table 1. The technical characteristics of models of laser distance sensors that determine the distance from $100 \mathrm{~m}$ to $3 \mathrm{~km}$

\begin{tabular}{|c|c|c|c|c|c|c|}
\hline № & Manufacturer & Model & $\begin{array}{c}\text { The } \\
\text { maximum } \\
\text { range of } \\
\text { measurement }\end{array}$ & Permission & Output signal & $\begin{array}{l}\text { Measuring } \\
\text { frequency }\end{array}$ \\
\hline 1 & Sick & DME4000 & $130 \mathrm{~m}$ & & $\begin{array}{l}\text { SSI, Profibus, RS422, } \\
\text { DeviceNet, Hiperface }\end{array}$ & \\
\hline 2 & Sick & DME2000 & $130 \mathrm{~m}$ & & $0 / 4 \ldots 20 \mathrm{~mA}, \mathrm{RS} 232$ & \\
\hline 3 & Dimetix & DLS-C & $150 \mathrm{~m}$ & & $\begin{array}{l}\text { RS-232 / RS-422 } \\
\text { Profibus, SSI }\end{array}$ & $6 \mathrm{Hs}$ \\
\hline 4 & Sick & DMT & $155 \mathrm{~m}$ & & $\begin{array}{c}4 \ldots 20 \mathrm{~mA} \text {, Profibus, RS } \\
232, \mathrm{RS} 422 / \mathrm{RS} 232\end{array}$ & \\
\hline 5 & Sick & DMT10-2 & $155 \mathrm{~m}$ & & $\begin{array}{c}4 \ldots 20 \mathrm{~mA}, \text { Profibus, RS } \\
232, \mathrm{RS} 422 / \mathrm{RS} 232\end{array}$ & \\
\hline 6 & Leuze & AMS 200 & $200 \mathrm{~m}$ & $0,3 \ldots 0,7 \mathrm{~mm}$ & & $10 \mathrm{Hs}$ \\
\hline 7 & Sick & DMD & $240 \mathrm{~m}$ & & Profibus, Interbus, SSI & \\
\hline 8 & TR Electronic & LE-200 & $240 \mathrm{~m}$ & $0,1 \mathrm{~mm}$ & $\begin{array}{l}\text { Analog Modbus, } \\
\text { Profibus, SSI }\end{array}$ & \\
\hline 9 & Sick & DME5000 & $300 \mathrm{~m}$ & & $\begin{array}{c}\text { SSI, Profibus, RS422, } \\
\text { DeviceNet }\end{array}$ & \\
\hline 10 & Sick & DME3000 & $500 \mathrm{~m}$ & & SSI, Profibus, RS422 & \\
\hline 11 & Astech & LDM51 & $500 \mathrm{~m}$ & $0,1 \mathrm{~mm}$ & $\begin{array}{c}\text { Analog, relay, RS232 / } \\
\text { RS422 / RS485, } \\
\text { Modbus, Profibus, } \\
\text { Ethernet }\end{array}$ & \\
\hline 12 & TR Electronic & LLB-500 & $500 \mathrm{~m}$ & $0,1 \mathrm{~mm}$ & $\begin{array}{l}\text { Analog Modbus, } \\
\text { Profibus, SSI }\end{array}$ & \\
\hline 13 & Dimetix & FLS-C & $500 \mathrm{~m}$ & & $\begin{array}{l}\mathrm{RS}-232 \text { / RS-422 } \\
\text { Profibus, SSI }\end{array}$ & $200 \mathrm{Hs}$ \\
\hline 14 & Sick & DML & $1100 \mathrm{~m}$ & & $\begin{array}{c}4 \ldots 20 \mathrm{~mA}, \text { Profibus, RS } \\
232, \mathrm{RS} 422 / \mathrm{RS} 232\end{array}$ & \\
\hline 15 & Astech & LDM301 & $3000 \mathrm{~m}$ & & $\begin{array}{c}\text { Analog, relay, } \\
\text { RS232/RS422, Modbus, } \\
\text { Profibus, Ethernet }\end{array}$ & \\
\hline
\end{tabular}

Most laser distance sensors, which determine the distance to an object, are used in the construction industry to measure the distance between objects, for example, they can help us to build a smart home (automate turning on and turning off of the light in the room after installing and configuring the sensor 
in a certain way, or make the doors automatically open or close, etc.). The use of these sensors is almost useless without a programmable microcontroller and can be obtained separately.

Although the most commonly used sensors are infrared (IR) sensor, ultrasound (US) sensor and laser triangle (LT) sensor, the most expedient among these sensors are considered laser triangle sensors because, unlike other sensors, as the distance at which objects are detected increases in laser triangle sensor, the measurement accuracy does not decrease, but increases [4].

The dependence graph of the distance sensors is shown in Figure 1.

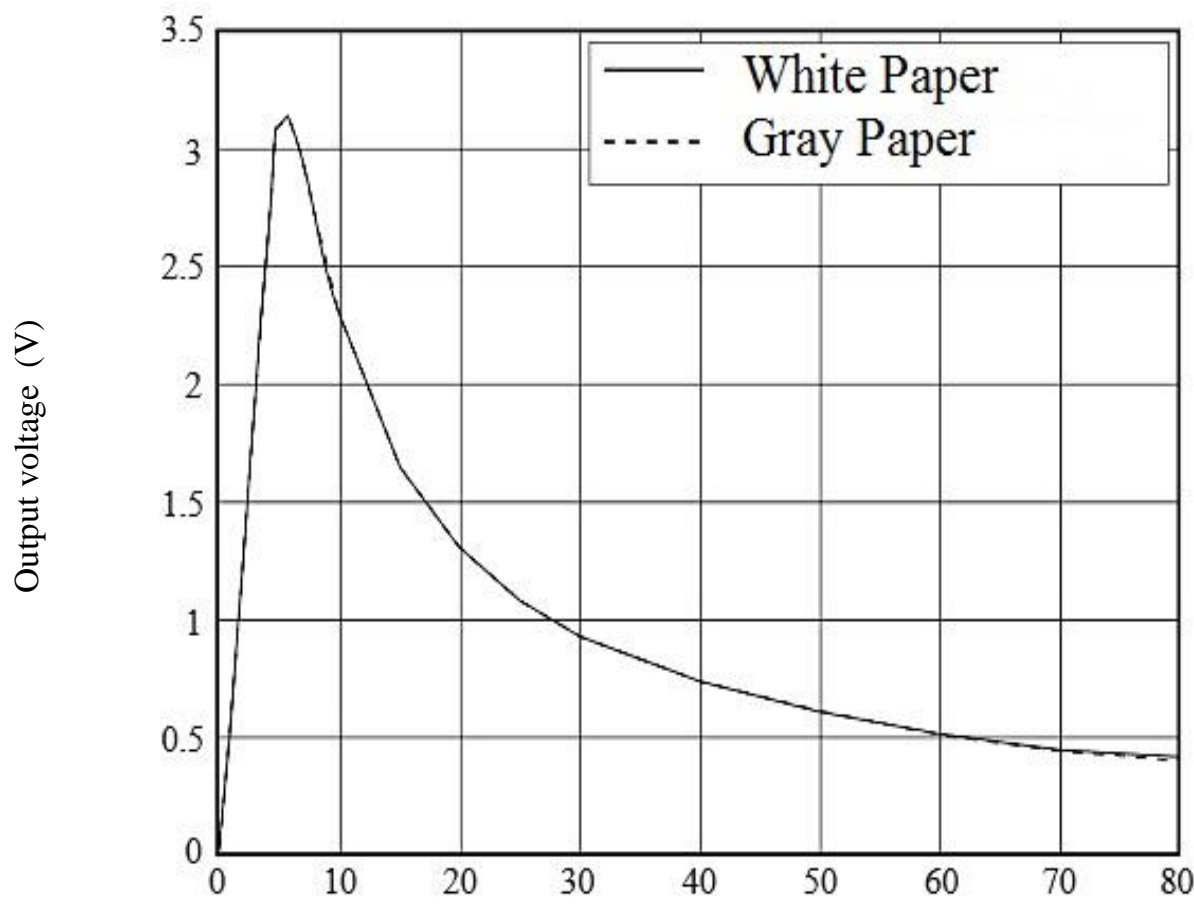

The distance to the reflected object L ( $\mathrm{sm})$

Figure 1. Dependence graph of distance sensors [5].

There are various sensors and methods to determine the distance to the object with high accuracy and increase the accuracy of the determination, one of which is a stereo vision method to recognize the distance to the object using a modern YOLO computer vision detector using a trianglulation. To calculate the distance between the camera and the object, the image is transmitted from the camera to the object classification based on a modern YOLO computer vision detector, in which objects are first classified according to certain parameters and color the distance from the object to the camera is calculated. The advantage of this method is the low cost of camera-based equipment, and the disadvantage is that errors can occur when finding the exact point of contact of the object with the ground and when changing the image. When the image changes or due to environmental factors, the camera malfunctions, resulting in erroneous images, errors, inaccurate information, and inaccurate distance to the object [6].

Another method to determine the distance to the object with high accuracy and increase the accuracy of detection is a new calibration method for the multi-view laser Doppler speed sensor system, which optimizes all laser parameters, correlates the parameters directly with the motion perception model, increases accuracy. However, the disadvantage of this method is that the sensors are not very resistant to environmental factors and require more material costs, so this method is not very appropriate [7].

From our research, as well as the advantages of sensors and methods, we can conclude that the proposed complex method provides flexibility due to its ability to determine a distance of thousands of 
meters over a wide measuring range, and therefore can be used to cope with various practical problems. The block of auxiliary sensors of the structural and functional model based on the proposed method allows to control of the characteristic parameters of external influences to reduce environmental impacts, and at the same time, these sensors immediately respond to a serious threat by recording the movement of a foreign object allows you to evaluate.

\section{MATERIAL AND METHOD}

\subsection{Advantages and Disadvantages Of Laser Triangle Sensors With Lidar Type Sensors, Their Comparative Analysis}

To study the state of the object, there are many methods and means to increase the accuracy of such characteristics as determining the distance to the object with high accuracy, inclination, color parameters, etc., and of them, the advantages and disadvantages of lidar-type sensors, laser sensors, and visible range sensors, their comparative analysis have been considered in the article.

Lidar-type sensors differ from other sensors due to their advantages such as being able to see the accuracy of processing of the obtained information, a wide range of applications in various security systems, everything around in more detail and with high accuracy, and the things being seen by them cannot be detected by another sensor or device, etc. These sensors being sensitive, i.e. their rapid destruction under the influence of the environment, i.e. they're being really sensitive to weather conditions (rain, snow, fog, and other weather conditions) and the terrain, their negative impact on the system's operation due to their being contaminated, i.e. at this time they provide false information about the object and being unable to work by the production indicators, being able to see the same part of the road to be measured only two or three times per second, their obtaining and reading less information, they're requiring higher financial costs are their disadvantages [8].

The advantages that distinguish the group of sensors created on the base of triple configuration of laser sensors from other sensor are their having high detection range using the visible part of the spectrum, having the ability of high accuracy and reproducibility, the sensor being easy to be installed and not requiring high maintenance costs, used materials and high level of protection and the use of these devices in difficult conditions, high resolution regardless of the color and material of the object, repetition and accuracy of measurements, high optical noise resistance of sensors due to laser beam monochrome, their ability to determine the geometric parameters of the research object, measurements, level difference, smoothness, surface curvature, objects, the sensors being economical due to low power consumption, ease of installation, technical characteristics of sensors, their ability to measure the angle of inclination of the tested surface and take this angle into account to obtain the accurate value of distance, however, their being really sensitive to environmental influences and the high cost of the sensor as a result of the influences under which the sensor becomes unusable, as well as the relatively high cost of the input control system of these sensors are their disadvantages.

When using this method, the sensor should only be used in suitable environmental conditions: temperature and humidity should not exceed the norm, the presence of dust on the surface of the sensitive elements of the sensors can lead to erroneous results - errors, laser sensors to each other and photoelectric optical interactions with sensors should be excluded.

From the comparative analysis and advantages and disadvantages of laser triangle sensors with lidartype sensors, we conclude that although lidar-type sensors determine the distance to the object as high accuracy as laser triangle sensors, they're seeing less distance per second and reading false information during contamination, requiring more cost, they're being more sensitive to environmental influences, makes it more expedient to use laser sensors in a triple configuration.

\subsection{The Proposed Method}

When selecting any method or tool, the measurement range and measurement accuracy, sensor performance characteristics, operating temperature range, opportunities to measure distance and determine it with high accuracy, and other parameters should be taken into account. To increase the 
accuracy of determining the distance to the object, obtain more accurate measurements, a laser triangle method with a certain structural and functional model was proposed using 3 laser sources, and the essence of this method is to conduct research using sensors arranged in a triangular shape at different angles of inclination. The proposed method is based on measurements with an optical sensor having a transmitter and a matrix-shaped optical receiver for the visible red part of the light spectrum of the laser beam as a source. If the beam is reflected from a smooth mirror surface, the measured distances to the object will increase significantly, and a very difficult calibration will be required. The method is intended to be used in various measurement systems allowing easy adjustment to detect small objects, maximum measurement accuracy and wide range of distances, measure linear dimensions, density, profile, surface roughness, internal and external diameters by contactless method, and precision contactless preparation of parts and it is also possible to observe the machine or its moving or vibrating parts at high speed, to measure the distance between the Earth and the Moon with the help of advanced technology, and the typical values for the accuracy of such measurement techniques are ten percent of the distance to the object.

At the same time, the mentioned sensors have the advantages of accurately determining the distance to the object, immediate response to outside interference in the protected area, as well as completely silent operation and low power consumption. Compared to other methods, the proposed method has higher accuracy, allows unambiguous measurements over long distances, and is more suitable for commonly reflected targets.

However, the sensitivity of the sensors to the environment hurts the operation of the sensor, as well as hot and cold temperatures, sudden changes in temperature, humidity (rain, snow, or moisture), wind, dust, thunderstorms, can lead to erroneous results or errors, sensor destruction or fuse blowing, etc and this affects the accuracy of the sensors, and thus, environmental conditions and both static and dynamic components of these factors should always be taken into account.

The advantages and disadvantages of the laser triangle method are shown in Table 2 [9].

Table 2. Advantages and disadvantages of the laser triangle method

\begin{tabular}{|c|c|}
\hline Advantages & Disadvantages \\
\hline High accuracy & Rapid breakdown \\
\hline High speed & High material cost \\
\hline High quality & Sensitivity to the effects of environmental factors \\
\hline Simplicity & $\begin{array}{l}\text { Incorrect results or errors due to environmental } \\
\text { factors }\end{array}$ \\
\hline Low energy consumption & Ability to accurately visualize local curves \\
\hline Quiet operation & \\
\hline $\begin{array}{l}\text { Ability to view "insignificant" assigned Skyler } \\
\text { areas }\end{array}$ & \\
\hline
\end{tabular}

The effects that can cause laser triangle sensors to read correctly and accurately and to fail them in a short period are shown in Table 3 [10].

Table 3. External effects on the laser triangle sensor

\begin{tabular}{|c|c|}
\hline Proper Sensor Alignment/Fixturing & Environmental conditions \\
\hline Mounting & Temperature \\
\hline Temperature & Other environmental conditions \\
\hline Vibration & \\
\hline Reference Surface & \\
\hline
\end{tabular}

\subsection{Structural Model Of The Proposed System}

The proposed method provides a structural and functional model of the intelligent system to increase the accuracy and truthfulness of measurement results obtained from sensors. 
Along with a set of auxiliary sensors designed to reduce the effects of the environment, the measurements are designed as complex measurements in the visible range. As it can be seen in the

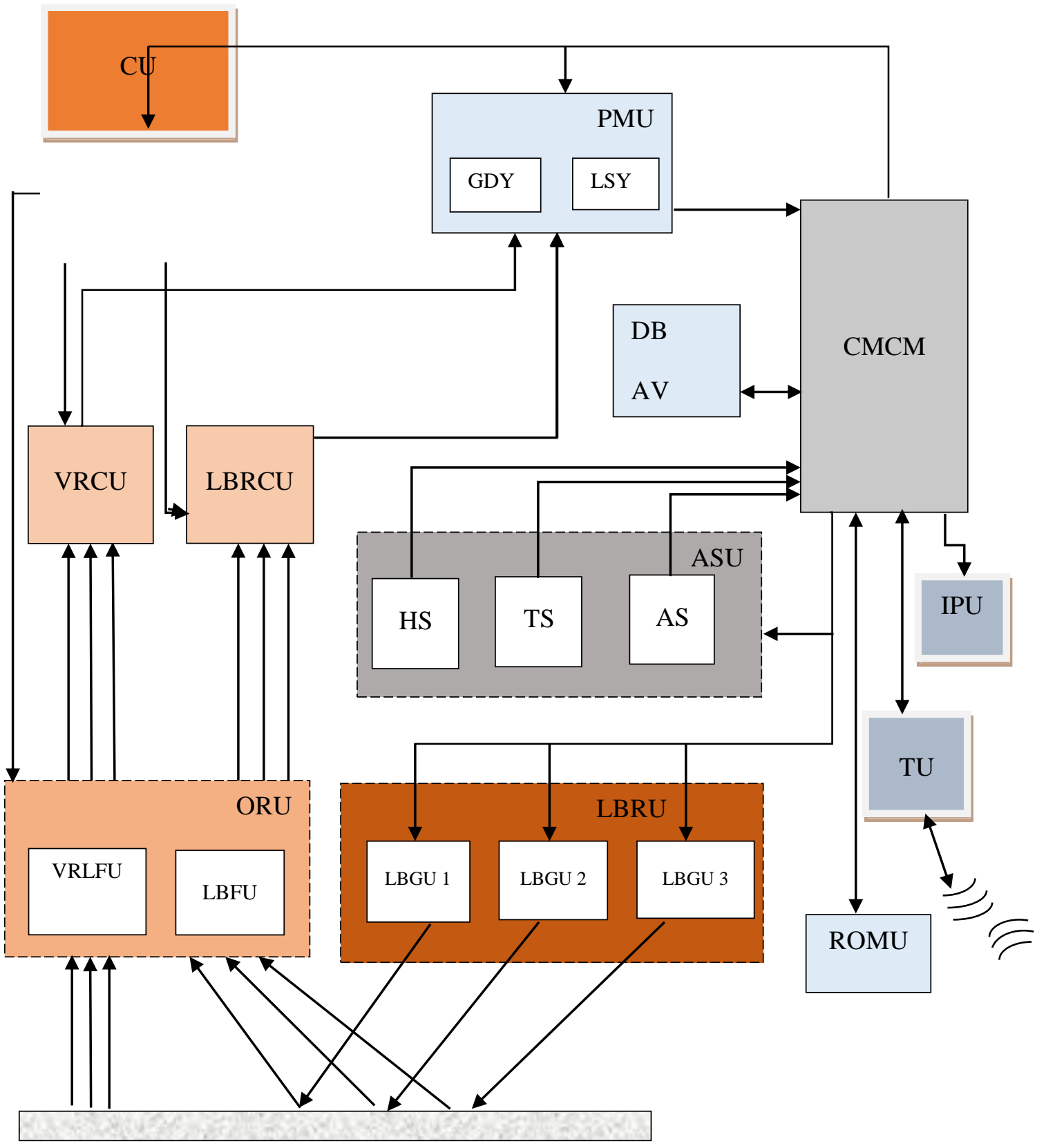

Figure 2. Structural model of the intelligent system

figure, the laser source constructed at 3 different inclinations consists of laser generation unit (LGU) controling it, the visible range light filter unit (VRLFU) and the optical receiver unit (ORU) consisting of laser beam filter units (LBFU), optical receiver and conversion unit (ORCU) for receiving and converting isolated signals (VRCU for visible range and LBRCU for laser beams) according to the corresponding wavelength of this unit, control unit (CU), which is controlled by the Central Microcontroller allowing to control the operation of optical receivers and conversion units, primary memory unit (PMU) which remembers the measurement results on the corresponding channels (GDY and LSY) of ORCU, temperature sensor (TS), humidity sensor (HS), airborne aerosol detection sensor (AS), etc., auxiliary sensors unit (OSU), which allows to control the characteristic parameters of external influencing factors, transmission and reception unit (TRU), which provides the transmission 
of results to other distances and systems, read-only memory unit (ROM) for storing the final results processed and accompanied by the appropriate identifiers; indication and print unit (IPU), which visualizes and records the results, the database (DB), which includes the limit values of the influential parameters along with the main indicators corresponding to the relevant research object, digital control and processing unit - central microcontroller module (CMCM), which participates in all stages of the measurement and control process performed by the system, processes the results in accordance with the requirements of the appropriate functional model allowing to make decisions based on the measurement results. The primary memory unit stores information concerning both ranges before transferring it to the $\mathrm{MC}$, the control unit controls the operation of the entire laser receiver, besides it controls the parameters of VRCU and VRRU elements according to the indicators of auxiliary transmitter unit sensors, MC has the ability to monitor the operation of all sensors and process measurement data allowing to calculate the distance to each of the laser sources, calculate the angle of inclination of the test object, estimate the correction value of the distance between the sensor and the sensor being tested, and MRU allows to transmit the data to the computer, global and local area network, indicator, printer, etc. In this case, as a result of processing results and comparative analysis of relevant indicators stored in the database, the limits of deviations are determined and appropriate decisions are made. The system has the functions of regular surface control and correction, cancellation of measurement results and repeated measurement depending on the results of deviations, warning about critical limits to appropriate distances and maintenance of measurements, exchange of information with other devices and systems if required, etc. [11].

\section{RESULT AND DISCUSSION}

It discusses noise sources, including surface texture, stains, beam deflection, and asymmetry, as well as an original approach to the development of the laser triangle method.

The results of our research can be summarized as follows:

- Dependence on local curvature prevents the loss of small details, which shows the advantage of using this method. This method is very simple to implement and provides the ability to view "nonmeaningful" defined Skyler areas, and it is an ideal method for displaying normally defined 3D Skyler areas.

- The sensor uses a laser beam (triangle method) to measure distance and angle of inclination with excellent temperature stability, and this approach allows to increase the accuracy and use of measuring equipment. It can be used effectively in many technological processes (distance measurement, etc.) incar control systems, robotic guidance systems, and other applications that require contactless distance measurement.

- Among the 7 models of the laser triangular sensor are RF600 and RF603HS, which have a wide range of technical characteristics, high-precision distance to the object, measuring range from 10 to $2500 \mathrm{~m}$, dimensions 170x61 x31 and weighing 500 grams. these are considered high-speed laser triangle sensors.

- The laser triangle method allows you to determine the distance or position to the object through the geometry of the triangle, and research has been conducted on how to measure distances using this method. This method has been shown to have exceptional capabilities for measuring distances up to thousands of meters, and severe limitations for shorter distances, and in the future, with advances in technology and improved integrated circuits, it will be possible to improve performance at less than one meter.

- Lidar-type sensors have been identified as the key technology to ensure the high-precision, safe landing of robots and crew aircraft on the moon in the future.

\section{CONCLUSION}

The article proposes a modern method to increase the accuracy of distance determination and uses this method to build a structural and functional model to increase the accuracy of measurement results obtained from sensors. From our research, we conclude that the proposed complex method, unlike other methods, is ideal for accurately determining the distance to the object, is produced from inexpensive parts, is very cost-effective for measurement, and can be detected at very long distances, a 
well-focused laser beam allows you to accurately locate small objects and determine the distance to the object with high accuracy.

\section{REFERENCES}

1. Young - Soo Suh, "Laser Sensors for Displacement, Distance and Position", Sensors, Vol.19, Issue 8, Pages 4, 2019.

2. Veiko, V.P., Petrov, A.A., Samokhvalov, A.A. "Introduction to Laser Technology. Basic lecture notes for the course "Laser technologies" edited by V.P. Veiko", St. Petersburg, P. 161, 2018.

3. Морозова, А.В., «Бесконтактные методы измерения расстояния в системах автоматического контроля», Бакалаврская работа, Томск, Россия, 94 с., 2021.

4. Fonseca, J. A. S. D., Baptista A., Martins M. J., Paulo N. Torres J., Distance Measurement Systems Using Lasers and Their Applications, Applied Physics Research, Vol. 9, No. 4, Pages 33-43, 2017.

5. Berkovic, G., Shafir, E., "Optical methods for distance and displacement measurements", Advances in Optics and Photonics, Vol.4, İssue 4, Pages 441-471, 2012.

6. Бурибаев, Ж., Меретбаев, Т., Ешмухаметов, А., Амиргалиев, Е., «Обнаружение и расчет координат обьекта с использованием стерео зрения для автоматической уборки урожая», Вестник КазНИТУ №5, Алматы, Казахстан, 11 с., 2020.

7. Hu, Y., Miyashita, L., Watanabe, Y., Ishikawa, M., "Visual Calibration for Multiview Laser Doppler Speed Sensing", Sensors, Vol.19, Issue 8, Page 12, 2019.

8. Bräunl, T., "Lidar Sensors", Robot Adventures in Python and C, № 1, Pages 47-51, 2020.

9. Daneshpanah, M., Harding, K., "Surface sensitivity reduction in laser triangulation sensors", SPIE Optical Engineering + Applications, Pages 9, San Diego, California, United States, 2011.

10. Blanco, D., Fernandez, P., Cuesta, E., Mateos, S., Beltron, N., "Influence of Surface Material on the Quality of Laser Triangulation Digitized Point Clouds for Reverse Engineering Tasks", Proceedings of $12^{\text {th }}$ IEEE International Conference on Emerging Technologies and Factory Automation, ETFA 2009, September 22-25, 2008, Palma de Mallorca, Spain.

11. Denisov, E.S., Salakhova, A.Sh., Timergalina, G.V., Nikishin, T.P., and Fazlyyyakhmatov, M.G., "Three-Beam Triangulating Sensor", IOP Conf. Series: Materials Science and Engineering, Vol. 86, Issue 1, Pages 656-670, Kazan, Russian Federation, 2015. 